\title{
Architecture and philosophy: The interdisciplinarity and coexistence of two worlds in the light of ethereality
}

\author{
Robert Łucka ${ }^{1, *}$ \\ ${ }^{1}$ Faculty Construction Architecture and Environmental Engineering, University of Science and \\ Technology, Bydgoszcz, Poland
}

\begin{abstract}
At the beginning of the $20^{\text {th }}$ century Marcel Duchamp stated that the art of the future would be growing out of philosophical roots. It seems impossible not to notice this fact in the contemporary world which surrounds mankind. However, the author of this article does not intend to analyse in depth details of manifestos of modernism or postmodernism. The article aims to signal the phenomenon of ethereal in architecture. The analysis of this phenomenon is based on the idea of the so called weak thought which functions in the world of philosophy and which was created by Constantin Noica and Ganni Vattimo. The mechanical transposition of terminology onto the world of architecture seems inadequate. The author of this article would not like to advocate the idea of weak architecture, let alone describe it. Therefore, he introduces the concept of ethereal architecture that contains the idea of inevitable ethereal as an integral part of existence. If someone does not succumb to delusion or wishful attitudes to reality, they will be able to notice the real sense and inner depth of everything that is weak and ethereal and that creates the immanent sphere of the surrounding world.
\end{abstract}

Characterised by errantry, the fight against ethereal of the surrounding scenery of life, especially the one typical of still nature, does not place a laurel wreath on the architect's head.

The feeling of malaise may be soothed be the idea stemming from the synthesis of architecture and philosophy, both of which can lead to the aware imagery of the passing time. This irreversible process seems easier to understand if it is subject to an analysis based on a broadly defined phenomenon of culture.

\section{In search of common language}

The existence of a human being is constituted by the following elements: location (being placed in the world, in the here and now, in a specific language, in a specific body, in a historical epoch, etc.) and understanding, i.e. the possibility of adopting an active and creative approach to the surrounding reality [1]. The perception of the surrounding world is determined by multiple subconscious and preliminary beliefs and judgements which subjects carry in themselves and which have a significant influence on the way a given phenomenon is approached.

\footnotetext{
* Corresponding author: lucka.robert@gmail.com
} 


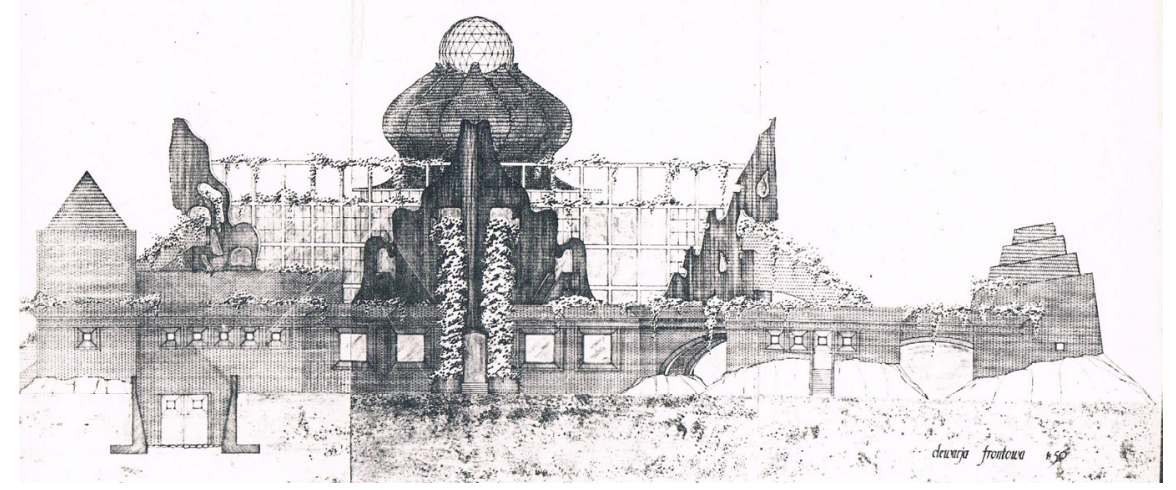

Fig. 1. A dialogue with history in the design of a facility created for lifelong architectural education, 1986, author Robert Łucka.

The unity of analysing phenomena of culture, including architecture and philosophy, through the prism of names that represent them or refer to them enables the subject to access these objects by well-known and comprehensible meanings of analysed signs that create the code of certain ideas. The message encoded in the object and its deciphering may reach the subject in the form of a language enriched by emotions. The spectrum of interpretations of this concept seems considerably broad, ranging from gestures through various alphabets, languages of various arts, including architecture, to the spoken language.

The phenomena mentioned above bring to mind the concept of semiotics, which can be explained by the dictionary of linguistic terminology (Warszawa, PWN, 1969) and which is briefly defined as, "a science investigating the nature and functions of signs in general from the logical point of view. The name is used interchangeably with semiology" (translated by the author). Such a definition contains the idea of "culture" perceived also as a process of communication. Not only does it mean communication between two subjects, but it also means a meaningful contact between ethereal worlds. Semioticians of the Tartu-Moscow School of Semiotics state that culture encompasses a static and object-based sphere alongside with a system of dynamic determinants and their images whenever we think about messages carried by encountered works of art, such as books, paintings, sculptures, architecture, etc., codified and fully-defined by the sender of the text. It is true also for, "meaningful sequences of symbols, such as for instance all types of rituals ... and means used to communicate, individual symbols (and their elements), all of which make up an utterance" (translated by the author) [2], as well as the ones connected with the process of etherealing.

It may be said that it happens frequently that images which are non-existent but still linger in human memory are more inspirational, valuable and carry a clear message. Would the Hanging Gardens of Babylon have stood the test of time in the context of contemporary advances of construction and computer technologies? Isn't it a better option when they keep growing in our imagination along with the development of technology and expansion of virtual reality? Thanks to that the legendary gardens did not grow small and did not lose their shine; they still can amaze and win admiration. The perspective on ethereal matter depends on several factors; firstly, on the time span that covers the period following its degradation; secondly, on the degree of emotional involvement in the original image of the etherealing reality. A different sense of zeal and emotions will be triggered by an intention to restore a medieval castle inhabited by one of knights of the Cuyavia region as compared with the determination to rebuild the Old Town in Warsaw, which was brought back to life again as a symbol of recovering from the trauma of the war hecatomb. 


\section{Weak thought}

This living memory, close to poetical mimesis, may trigger the mechanism of active participation in the ongoing motion of the surrounding world, which may often seem strange.

Everyone carries in themselves the idea of "other", "weakness" and "dialogue", all of which are the milestones of the postmodern philosophy of Emmanuel Le'vinas. The metaphors of ethereal and fragility may be found in the works of Constantin Noica and Gianni Vattimo. The weakness of existence is a horizon of understanding the postmodern reality and understating the being. What is transcendent and makes experiencing the world possible is infirmity [3]. The search for permanent objects of cognition in the surrounding reality is subject to devaluation. What seemed to be constant turned out to be an instance of pretence lacking any substance. An immanent element of life is finiteness, a constant play of interpretation and historicity imbued in mortality. The way of thinking still present at the beginning of the $20^{\text {th }}$ century developed from the traditional version of Aristotle's metaphysics: it was a search for a beginning, a foundation highlighting the significance of the first principles, the so-called archai. The concept of strong thought typical of this philosophical movement was centred on the concepts of fulfilment and finality. The postmodern idea of weak thought, on the other hand, as opposed to the clarity of its forerunner, does not have an unambiguous essence that would be easy to recognise. Weak thought does not exist: it happens or is encountered. The power stemming from this metaphor lies in the flexibility of this concept. Weak thought is close to the category of narration; it is because it sees a being from the point of view of its being accidental, its happening, taking place, or occurring in time as well as because it sees itself only as a story about being which is based not on a full and universal theoretical design, but on the sphere of local and partial or narrative justifications [4]. The idea of weak thought is understanding the being as the process of happening which leaves signs, symbols, cultural messages created in subject-based contexts. Bearing in mind La carte postale by Jacques Derrida, in which the author mentioned a message which does not convey "something" and which is not sent from a specific source and does not have a clear addressee, we may state that there exist messages, created from multiple rather than single sources, which leave a variety of traces and make references to other traces. This fragmentation of messages is not negative, since it is a proof of existing intentions, thoughts and creating a sing, all of which are elements of post-metaphysical philosophy, which endeavours to analyse the being outside its categories of being present and representing.

Weak thought, especially as seen by Vattimo, tries to become a type of koine of contemporary thought. It collects and summarises experiences of, for instance, postHeidegger hermeneutics, deconstruction, post-structuralism, which create the image of late modern culture and present a diagnosis of its condition. "Weak thought is a thought presenting philosophy after different states of crisis it experienced at the end of modernism - after the crisis of the subject, the crisis of representation, the crisis of philosophy itself as a tool to learn about the world [5].

\section{Evanescent architecture}

It seems difficult to copy the philosophical terminology onto the field of architecture. Thought can be "weak" and can analyse the accidental being; it may be devoid of clear meaning, but still it does not lose its carrying capacity and poignancy. It is not worth writing about "weak" architecture. Therefore, following the thoughts of Levinas, Noica and Vattimo, all of whom examined the melancholic and nostalgic understanding of an elusive 
and ethereal being, the author of this article suggests introducing the concept of ethereal architecture.

All instances of the existence of buildings demonstrate qualities of being ethereal and weak. Testing this hypothesis will depend only on determining the time unit during which the process of changes of the form, function or the loss of the material quality of the object takes place. Existing within a fraction of the history of mankind, we may be under the pretence of architecture being constant and long-lasting. However, this is only a false impression resulting from a narrow time horizon. Just like weak thought, ethereal architecture has an innate quality of changing; both are not stable and durable beings; they only "happen" in time. Architecture is a record of the process of creation, a sum of wishes, ambitions and technical skills of people living in a specific epoch, during which its being materialised. Existing in a given time and space leads to dialogue between next generations that may add other elements to the original form. They carry new functions, trying to make the message, which is constantly flowing from the spatial construction towards the subject, modern and comprehensible. There are few instances of architecture caught unaltered in a given moment of the bygone era. There are obvious instances, e.g. sacral buildings that are "painfully gothic". It is impossible to find Renaissance altars, Baroque confessionals or eclectic chandeliers inside them. Gothic, gothic, gothic... No layers of the dynamics of the previous generations, a true mummy of the former time. It seems though that such narration of architecture devoid of historic layers is a rare occurrence.

Certainly, it is not an instance of ethereal architecture. Since it is a temporary phenomenon which is created by, e.g. the material signs of existing in culture and space that have been discussed above:

- architecture of sand and stones includes lost cities of North Africa, palisades of pagan settlements and underground remnants of medieval castles. It encompasses everything that has been covered by soil and which still can be unearthed even to a minor degree. It is a true museum of imagination full of misty images and clear records of dreams. Literature is the perfect soil for this architecture: Jorge Luis Borhes, Umberto Eco or Julio Cortazar.

- architecture of materialised silence is a gallery of memories in the open space. The Parthenon, the coliseum in Verona and the Roman Forum are lasting remnants, places where you should not add anything and where nobody will allow you to take anything away. It is amazing with its majesty when among silent stones visitors can picture in their minds colourful crowds gathering there. It is like a piece of an old photograph - adorable though torn.

- architecture of nostalgia is only space for memories as well as frenetic and hopeless processes of recalling the bygone era. It is often an irrational escape that lacks any aesthetic point into the non-existence of forms that used to be fascinating. The agent in the process may be either a human or nature. A good illustration may be the Crystal Palace, the railway station in Katowice or Giumri, a city in Armenia that was destroyed by an earthquake in 1988. This architecture is left with photographs, memories and the bitterness of the passing time.

- architecture of a sketch is created by designs that have never been built, visionary images that have fertilised the minds of generations. This architecture lives in the hearts of its creators; it is possible to experience it on pages of books, photographs or in virtual space. It can be seen, and the imagination allows visiting its interiors and being amazed by its proportions. Thinking and being are the same thing (translated by the author) [6]. Among creators of the architecture of a sketch one should list the following names: Giovanni Battista Piranesi, Etienne-Louis Boullee, Antonio Sant'Elia, Leon Krier or Zdzisław Beksiński. While experiencing this type of architecture, you can feel a strong sense of 
an unfulfilled need or of being lifted $10 \mathrm{~cm}$ above the ground with nothing to lean on and with no materialised touch of at least one stone of the amazing shape.

- architecture of the morning is an extremely elusive phenomenon created by clearly defined spatial forms. Their colourful gallery includes works by, e.g. Javacheff Christo and Anish Kapoor; you can also include here summer pavilions in the Serpentine Gallery in London or objects presented at the Venice Biennale of Architecture. Alas, as in a magical movie in which the main character was viola da gamba the power rests with the words, "all mornings of this world will be gone".

- architecture of the theatre of life is full of interpretation, poetry and dresses up in costumes appropriate for parties of the changing epochs. It is strongly humanistic and open to dialogue. Its core of experience is not consciousness, but meeting the other... it is communication that creates [its] sense [7]. This trend may be illustrated by living and constantly changing structures, of which mainly functions continue evolving; however, the form is subject to transformations as well. Thanks to these processes it is possible to encounter a dynamic and permanently energetic organism which is resistant to the destructive powers of the time machine and which is left untouched by the historical dust carrying oblivion... Suffice to mention, lofts, galleries and hotels built in post-industrial buildings or the enormous funeral centre in Paris, which recently hosted workshops run by Philippe Starck. It is also worth mentioning other places, e.g. the colourful architectural mosaic of the Wawel castle, the Prado Museum or Venice. This charming story frozen in brick and stone is written down into the structure of cities by generations following their ancestors. Thanks to it, texts create an identity of communities that keep accepting and interpreting them (translated by the author) [8].

\section{Conclusions}

Developers and architects are wanderers who leave traces on the path of time that runs close to a sandy and windy desert. Their personalities and materialised sings of talent are like elements of the living cathedral created digitally by Tomasz Bagiński. Only humility and the knowledge of a distant horizon of time can help to perceive works of architecture in the adequate context of ethereal. A narrow perspective of everyday creates only wishful pretence of a constant being. It is only pretence full of elusive ethereal created from the need to search for durable foundations of human existence. It should be borne in mind that the present time is just a temporary bridge between the bygone time ornamented with memories and a misty hope for the future.

\section{References}

1. A. Przyłębski, (Gadamer, 26, 2006)

2. G. Vattimo, (Teksty Drugie” Dialektyka, różnica, myśl słaba, 5, 132, 2003)

3. U. Eco, (Pejzaż semiotyczny, 9,1972)

4. A. Zawadzki, (Literatura a myśl słaba, 62, 2009)

5. A. Zawadzki, (Literatura a myśl słaba,163, 2009)

6. M. Heidegger, (Identyczność i różnica, 65, 2010)

7. B. Skarga, (Tożsamość i różnica, 142, 2009)

8. P. Ricoeur, (Miłość i sprawiedliwość, 68, 2010) 